\title{
Comparison of estimates of under-nutrition for pre-school rural Pakistani children based on the WHO standard and the National Center for Health Statistics (NCHS) reference
}

\author{
Rozina Nuruddin ${ }^{1,2, *}$, Meng Kin Lim ${ }^{3}$, Wilbur C Hadden ${ }^{4}$ and lqbal Azam ${ }^{1}$ \\ 'Department of Community Health Sciences, The Aga Khan University, Karachi-74800, Pakistan: ${ }^{2}$ Pakistan and \\ Department of Community, Occupational and Family Medicine, National University of Singapore, Singapore \\ 1 17597, Singapore: ${ }^{3}$ Department of Community, Occupational and Family Medicine, Yong Loo Lin School of \\ Medicine, National University of Singapore, Singapore 117597, Singapore: ${ }^{4}$ National Institute on Aging, \\ Bethesda, MD 20892, USA
}

Submitted 10 April 2007: Accepted 3 April 2008: First published online 27 May 2008

\begin{abstract}
Objective: To compare estimates of under-nutrition among pre-school Pakistani children using the WHO growth standard and the National Center for Health Statistics (NCHS) reference.

Design: Prevalence of stunting, wasting and underweight as defined by WHO and NCHS standards are calculated and compared.

Setting: The data are from two cross-sectional surveys conducted in the early 1990s, the time frame for setting the baseline for the Millennium Development Goals: (i) National Health Survey of Pakistan (NHSP) assessed the health status of a nationally representative sample and (ii) Thatta Health System Research Project (THSRP) was a survey in Thatta, a rural district of Sindh Province.

Subjects: In all, 1533 and 1051 children aged 0-35 months from national and Thatta surveys, respectively.

Results: WHO standard gave a significantly higher prevalence of stunting for both national $[36 \cdot 7(95 \%$ CI 33.2, 40.2)] and Thatta surveys [52.9 (95\% CI 48.9, 56.9)] compared to the NCHS reference [national: $29 \cdot 1(95 \%$ CI $25 \cdot 9,32 \cdot 2)$ and Thatta: $44 \cdot 8$ (95\% CI $41 \cdot 1,48 \cdot 5)$, respectively]. It also gave significantly higher prevalence of wasting for the Thatta survey [22.9 (95\% CI 20.3, 25.5)] compared to the NCHS reference $[15 \cdot 7(95 \%$ CI $13 \cdot 5,17 \cdot 8)]$. Differences due to choice of standard were pronounced during infancy and for severely wasted and severely stunted children. Conclusions: Pakistan should switch to the robustly constructed and up-to-date WHO growth standard for assessing under-nutrition. New growth charts should be introduced along with training of health workers. This has implications for nutritional intervention programmes, for resetting the country's targets for Millennium Development Goal 1 and for monitoring nutritional trends.
\end{abstract}

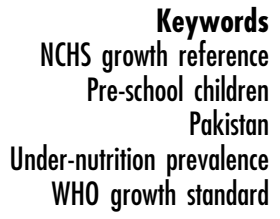

Interpretation of the growth of a population is largely dependent on the growth reference standard used ${ }^{(1)}$. Based on the 1977 National Center for Health Statistics (NCHS) growth reference, Pakistan is one of three countries (with India and Bangladesh) frequently cited to have in combination more than half of the world's undernourished children ${ }^{(2)}$. Among eight South Asian countries, Pakistan ranks 3rd, 4th and 6th, respectively, for prevalence of wasting (13\%), underweight (38\%) and stunting (37\%) among under-five children ${ }^{(2)}$.

Suitability of the NCHS dataset as an international growth reference has been challenged on serious technical grounds ${ }^{(3-7)}$ and its continued use as a reference to monitor individual growth or to estimate prevalence of under-nutrition is being discouraged ${ }^{(8-10)}$. To address deficiencies in the NCHS reference, the Centers for Disease Control and Prevention (CDC) produced a revised reference in $2000^{(1,3)}$ and WHO organised and sponsored a Multicentre Growth Reference Study (MGRS) between 1997 and 2003 to develop new growth standards ${ }^{(11-14)}$. In this study, growth of 8500 children from affluent families was assessed. These children came from widely differing ethnic backgrounds and cultural settings (Brazil, Ghana, India, Norway, Oman and USA). They were reared following healthy practices, which included exclusive or predominant breast-feeding for at least 4 months and the maintenance of a non-smoking environment. WHO released a new growth standard for infants and young 
children in April 2006 (http://www.who.int/childgrowth/ en/ $)^{(15)}$ and recommended its use in preference to the NCHS reference to assess children regardless of ethnicity, socio-economic status and type of feeding ${ }^{(16,17)}$. The new standard adopts a fundamentally prescriptive approach and not only serves as an international reference but also describes what might be considered as normal growth under ideal circumstances ${ }^{(18)}$.

Pakistan is among ninty-nine countries where the NCHS reference is currently used in the national programme ${ }^{(19)}$. Recently, field testing of the new WHO growth standard for under-five children was carried out at two health centres in Karachi ${ }^{(20)}$. Comparison of the estimates of under-nutrition derived from the WHO standard and the NCHS reference in Bangladesh ${ }^{(21)}$ suggest significantly higher prevalence of underweight, stunting and wasting during infancy using WHO standards. Since Pakistan is the third largest contributor of under-nourished children worldwide, it is highly relevant to examine the impact of this change of growth standard on various parameters of nutritional status by using information from a local population-based survey. In the present paper, we compare the estimates of wasting, stunting and underweight obtained from the WHO standard and the NCHS reference for the Pakistani population and discuss the implications of changing the growth standard for national child health programmes.

\section{Material and methods}

\section{Data sources and survey designs}

Data for this study are derived from two different sources, which include the National Health Survey of Pakistan (NHSP) (1990-94) and the Thatta Health System Research Project (THSRP) (1992-93). We chose NHSP and THSRP datasets because of their availability and suitability to address the study question. Both the surveys were conducted during the early 1990s, which is the time period that served as a baseline for setting Millennium Development Goals.

NHSP (hereafter referred to as national data) was a multipurpose cross-sectional survey conducted by Pakistan Medical Research Council (PMRC) under the technical guidance and support of NCHS in 1990-94. The details of sampling, design, survey instruments and quality control have been described elsewhere ${ }^{(22)}$. The main purpose of the survey was to measure the health status of the people of Pakistan, particularly high-risk groups such as children, mothers and the elderly. An Institutional Review Board at PMRC provided ethical approval for the survey ${ }^{(23)}$. The survey was modelled on the National Health and Nutrition Examination Survey (NHANES) of the USA and was modified according to the information needs of Pakistan. In brief, eight broad strata were created by dividing each of the four provinces into urban and rural areas. Through a two-stage stratified design, eighty primary sampling units (PSU) were randomly selected, comprising thirty-two urban blocks and fourty-eight rural villages ${ }^{(22)}$. From each PSU, thirty households were drawn systematically into the sample by taking a random start and a sampling interval. All residents of the households were included in the survey $^{(24,25)}$. In total, 912 urban and 1408 rural households were surveyed covering a total population of 18315 subjects. Although anthropometric information was available for children under 5 years of age, this study is limited to 1533 children aged $0-35$ months from 387 urban and 723 rural households. Overall $3 \cdot 1 \%$ of the household did not participate in the survey ${ }^{(22)}$.

THSRP (hereafter referred to as Thatta data) was a survey conducted by the Aga Khan University from November 1992 to February 1993 in Thatta, a rural district of Sindh Province, after approval from an Institutional Ethical and Review Committee ${ }^{(26)}$. The main purpose of the survey was to measure the health and nutrition status of the population and utilisation of health services. Using a three-stage stratified sampling, twelve Union Councils (UC) with fairly complete enumeration lists were identified. Villages (PSU) located within $5 \mathrm{~km}$ of the government health facilities (GHF) within selected UC were listed and mapped. Five to twelve villages were randomly selected from each service area, with a target to sample at least 250 households per GHF catchment area. In this way, a population of 24121 subjects from 2276 households and ninty-nine villages were surveyed. Overall the non-response rate was $9 \%$. Anthropometric information was available for 1051 children aged 0-35 months from 952 households and 95 villages.

\section{Data collection}

\section{Age information}

Mothers were interviewed to provide information about the child's age, which was estimated with the aid of local event calendars listing important events, festivals and moon cycles.

\section{Anthropometric measurements}

Trained field workers took anthropometric measurements of children. In the Thatta survey, child's weight was recorded to the nearest $0 \cdot 1 \mathrm{~kg}$ using a portable $25 \mathrm{~kg}$ spring balance Salter Scales (Salter England, West Bromwich, UK). Weighing scales were calibrated daily using $20 \mathrm{~kg}$ weight. During weighing, children were lightly clad and without shoes/slippers. Recumbent length (for children less than 24 months) was measured to the nearest centimetre by portable flat wooden boards with a sliding foot piece (locally manufactured by Pakistan Medical and Dental Council). For children older than 24 months, standing height was obtained. Severely malnourished children were referred to a local hospital or a health centre for further assessment and care.

\section{Data quality assessment}

Completed questionnaires were checked and validated by field supervisors daily in both the surveys. Questionnaires 
with inconsistencies were re-sent to the field for correction. Data quality was maintained by supervision and retraining of the field staff. The national survey also used end-digit preference ${ }^{(22)}$. Only $10 \cdot 2 \%$ of the children's height and $13 \cdot 2 \%$ of the children's weight were rounded to zero. A validation survey of 400 households was conducted within 2 weeks of the actual Thatta survey, for determination of data collection errors ${ }^{(27)}$.

Anthropometric information was missing for $18 \%$ and $30 \%$, respectively, of the national and Thatta subjects. For national data, responders were significantly younger $[$ mean age $=15.5$ months $(\mathrm{SEM}=0.51)]$ compared to nonresponders [mean age $=17 \cdot 4$ months $(\operatorname{sem}=0 \cdot 22)$ ]. There were significantly more boys (53\%) among responders compared to non-responders (44\%). For the Thatta survey however, age, gender, mean household income per capita and maternal education did not differ significantly by response status.

\section{Data management and analysis}

Measured heights and weights were converted to standard normal scores ( $Z$-scores) on the NCHS reference and the WHO standard distributions adjusting for child's age and gender with a software package named ANTHRO (available at http://www.who.int/nutgrowthdb). Z-score standard deviations were close to 1 , suggesting reasonable quality of the measures ${ }^{(28)}$.

Although WHO recommends taking a $Z$-score above +6 or below -6 as extreme values indicating measurement problems, we took +4 as the upper threshold of acceptable scores. This is because the probability of a child having a Z-score for weight-for-age (WAZ) or height-for-age (HAZ) greater than 4 is less than $0 \cdot 0001^{(29)}$, given that the means of WAZ and HAZ for a population like Pakistan are $-1 \cdot 4$ (Table 2 ).

To account for unequal selection probabilities and to reduce bias in variance estimation, weights were calculated as the inverse of the sample selection probabilities. To account for data clustering, analysis was performed with SUDAAN ${ }^{(30)}$ using the option of without replacement sampling design. Weighted prevalence of under-nutrition with $95 \%$ confidence intervals is presented.

Prevalence of under-nutrition (percentage of children aged 0-35 months) was calculated following convention $^{(21,31)}$ as the number of children with $Z$-scores less than -2 sD below the NCHS reference or WHO standard for the following nutritional parameters: wasting (weightfor-height), stunting (height-for-age) and underweight (weight-for-age). 95\% CI were calculated for each prevalence measure. Mild, moderate and severe malnutrition were determined using the relevant parameters of the reference population as below -1 and down to $-2 \mathrm{SD}$, below -2 and down to $-3 \mathrm{SD}$ and below $-3 \mathrm{SD}$, respectively. Mean $Z$-scores (and their SD) for undernutrition were calculated to compare the WHO standard and the NCHS reference.
Age-specific prevalence was calculated for seven age groups. During infancy, four age groups were created keeping in view the rapid growth velocity ${ }^{(32)}$. These age groups included 0-3, 4-6, 7-9 and 10-12 months. During the second and third years, to account for slower growth velocities and to accommodate smaller numbers, the age groups were defined as 13-18, 19-24 and 25-35 months. To permit comparison with Thatta data, we limit our analysis to children under 3 years of age from national data.

\section{Results}

As expected, average household size was smaller for national (8.3) than for Thatta data (10.6) and the literacy level was better for national (35\%) than for Thatta $(22 \cdot 1 \%)$ data. Greater proportion of the population belonged to low socio-economic status in the national sample (36\%) than in the Thatta sample (27.6\%).

Height, weight and age information were available for 1533 and 1051 children aged 0-35 months from the national and Thatta surveys, respectively. The gender distribution was similar in both datasets (53\% males). Mean ages (months) were younger for the national [boys: $8 \cdot 3(\mathrm{SEM}=0 \cdot 3)$ and girls: $8 \cdot 9(\mathrm{SEM}=0 \cdot 3)]$ compared to the Thatta sample [boys: $14 \cdot 0(\mathrm{SEM}=0 \cdot 4)$ and girls: $13 \cdot 0$ $(\operatorname{sEM}=0 \cdot 4)]$.

\section{Z-scores for under-nutrition}

Pakistani children are shorter and lighter than the reference populations (Table 1). The mean $Z$-scores for all three parameters did not differ significantly with the choice of reference. However, mean $Z$-scores for heightfor-age and weight-for-age were significantly lower for the Thatta than for the national sample.

\section{Prevalence of under-nutrition}

Prevalence of wasting was higher with the WHO standard than the NCHS reference in both the national (18\%: 14\%) and the Thatta (23\%:16\%) surveys (Table 2). The relative increase with the WHO standard was $26 \%$ for the national and $46 \%$ for the Thatta data. Similarly, stunting prevalence was higher with the WHO standard in both the national (37\%:29\%) and the Thatta (53\%: $45 \%)$ surveys, respectively, with the relative increase of $26 \%$ and $18 \%$. On the other hand, prevalence of underweight was lower with the WHO standard for both the national (32\%:36.5\%) and the Thatta data (46.5\%: 48\%), with the relative decrease of $15.5 \%$ and $4 \%$, respectively, compared to the NCHS reference.

\section{Prevalence of severe under-nutrition}

Prevalence of severely under-nourished children increased with the WHO standard compared to the NCHS reference (Table 2 ). The relative increase was greatest for wasting (national: $1 \cdot 8$ times and Thatta: twice), followed 
Table 1 Mean standard scores (Z-scores) and $95 \% \mathrm{Cl}$ for indicators of under-nutrition among Pakistani children under 3 years of age: comparison of the WHO standard and National Center for Health Statistics (NCHS) reference with data from the National (1990-94) and the Thatta (1992-93) surveys

\begin{tabular}{|c|c|c|c|c|}
\hline \multirow[b]{2}{*}{ Under-nutrition parameter } & \multicolumn{2}{|c|}{ Mean Z-scores for National data $(95 \% \mathrm{Cl})(n$ 1533) } & \multicolumn{2}{|c|}{ Mean Z-scores for Thatta data $(95 \% \mathrm{Cl})(n 1051$} \\
\hline & WHO & $\mathrm{NCHS}$ & WHO & $\mathrm{NCHS}$ \\
\hline $\begin{array}{l}\text { Weight adjusted for height } \\
\text { Height adjusted for age } \\
\text { Weight adjusted for age }\end{array}$ & $\begin{array}{l}-0 \cdot 9(-1 \cdot 0,-0 \cdot 8) \\
-1 \cdot 4(-1 \cdot 5,-1 \cdot 3) \\
-1 \cdot 4(-1 \cdot 5,-1 \cdot 3)\end{array}$ & $\begin{array}{l}-0.9(-1 \cdot 0,-0 \cdot 8) \\
-1 \cdot 5(-1 \cdot 6,-1 \cdot 4) \\
-1 \cdot 2(-1 \cdot 3,-1 \cdot 1)\end{array}$ & $\begin{array}{l}-1 \cdot 0(-1 \cdot 1,-0 \cdot 9) \\
-2 \cdot 0(-2 \cdot 1,-1 \cdot 9) \\
-1 \cdot 9(-2 \cdot 0,-1 \cdot 8)\end{array}$ & $\begin{array}{l}-0.8(-0.9,-0.7) \\
-1.8(-1.9,-1 \cdot 7) \\
-1.9(-2 \cdot 0,-1 \cdot 8)\end{array}$ \\
\hline
\end{tabular}

Table 2 Percentage prevalence $(95 \% \mathrm{Cl})$ of indicators of under-nutrition among Pakistani children under 3 years of age: comparison of the WHO standard and National Center for Health Statistics (NCHS) reference with data from the National (1990-94) and the Thatta (1992-93) surveys

\begin{tabular}{|c|c|c|c|c|}
\hline \multirow[b]{2}{*}{ Under-nutrition parameter } & \multicolumn{2}{|c|}{ National survey } & \multicolumn{2}{|c|}{ Thatta survey } \\
\hline & WHO & $\mathrm{NCHS}$ & WHO & $\mathrm{NCHS}$ \\
\hline Wasting & $18 \cdot 0(14 \cdot 9,21 \cdot 1)$ & $14 \cdot 3(11 \cdot 4,17 \cdot 2)$ & $22 \cdot 9(20 \cdot 3,25 \cdot 5)$ & $15 \cdot 7(13 \cdot 5,17 \cdot 8)$ \\
\hline Mild & $27 \cdot 1$ & $33 \cdot 4$ & $24 \cdot 9$ & $32 \cdot 0$ \\
\hline Moderate & $13 \cdot 0$ & $12 \cdot 5$ & $15 \cdot 4$ & $13 \cdot 2$ \\
\hline Severe & $5 \cdot 0$ & $1 \cdot 8$ & $7 \cdot 5$ & $2 \cdot \overline{5}$ \\
\hline Stunting & $36 \cdot 7(33 \cdot 2,40 \cdot 2)$ & $29 \cdot 1(25 \cdot 9,32 \cdot 2)$ & $52 \cdot 9(48 \cdot 9,56 \cdot 9)$ & $44 \cdot 8(41 \cdot 1,48 \cdot 5)$ \\
\hline Mild & $24 \cdot 5$ & $27 \cdot 3$ & $22 \cdot 7$ & $27 \cdot 2$ \\
\hline Moderate & $23 \cdot 3$ & $20 \cdot 1$ & $24 \cdot 9$ & $25 \cdot 7$ \\
\hline Severe & $13 \cdot 6$ & $9 \cdot 0$ & $28 \cdot 0$ & $19 \cdot 1$ \\
\hline Underweight & $31 \cdot 6(27 \cdot 7,35 \cdot 5)$ & $36 \cdot 5(32 \cdot 4,40 \cdot 6)$ & $46 \cdot 5(42 \cdot 1,50 \cdot 9)$ & $48 \cdot 4(44 \cdot 2,52 \cdot 6)$ \\
\hline Mild & $31 \cdot 9$ & $32 \cdot 7$ & $28 \cdot 5$ & $29 \cdot 4$ \\
\hline Moderate & $20 \cdot 3$ & $26 \cdot 0$ & $25 \cdot 7$ & $29 \cdot 8$ \\
\hline Severe & $11 \cdot 3$ & $10 \cdot 5$ & $20 \cdot 8$ & $18 \cdot 6$ \\
\hline
\end{tabular}
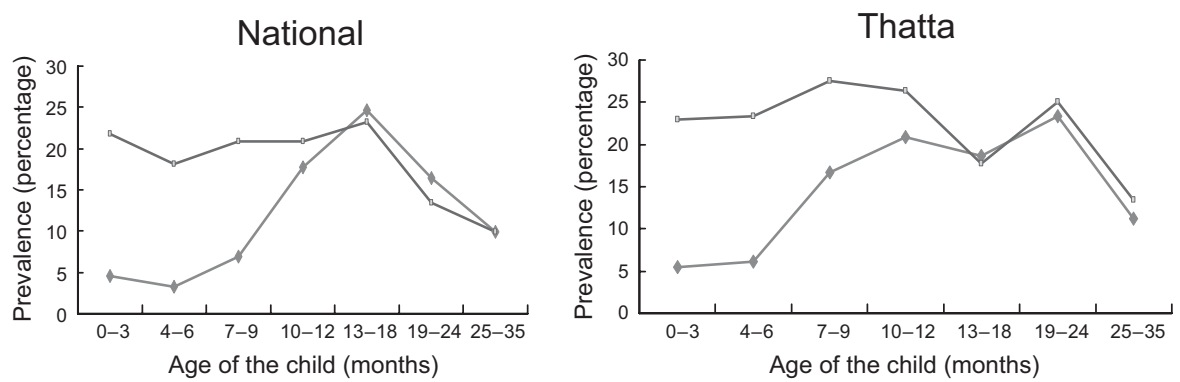

Fig. 1 Percentage prevalence of wasting by age with the WHO $(-\square)$ standard and the National Center for Health Statistics $(-\downarrow)$ reference for national and Thatta data

by stunting (national: $51 \%$ and Thatta: $46 \cdot 5 \%$ ) and underweight (national: $7 \cdot 6 \%$ and Thatta: $12 \%$ ).

\section{Age-specific prevalence of wasting}

For both the surveys, wasting prevalence was significantly higher with the WHO standard compared to the NCHS reference up to the first 9 months (Fig. 1). The two curves began to converge at 10-12 months of age, following which the two references produced similar results.

\section{Age-specific prevalence of stunting}

Stunting prevalence was similar across various age groups for both the surveys except for significantly higher prevalence obtained by the WHO standard for 25-35month-old children in the national survey and 0-3- and 19-24-month-old children in the Thatta survey (Fig. 2).

\section{Age-specific prevalence of underweight}

For both surveys, underweight prevalence was significantly higher with the WHO standard up to the first 6 months with a cross-over at 7-9 months (Fig. 3). For the rest of the ages, the WHO standard gave lower prevalence. The range of underweight prevalence across age groups was narrower with the WHO standard (40-50\%) than with the NCHS reference (20-60\%).

\section{Discussion}

\section{Impact of the WHO standard on prevalence of under-nutrition}

Estimates of under-nutrition obtained with the WHO standard and the NCHS reference varied by growth 

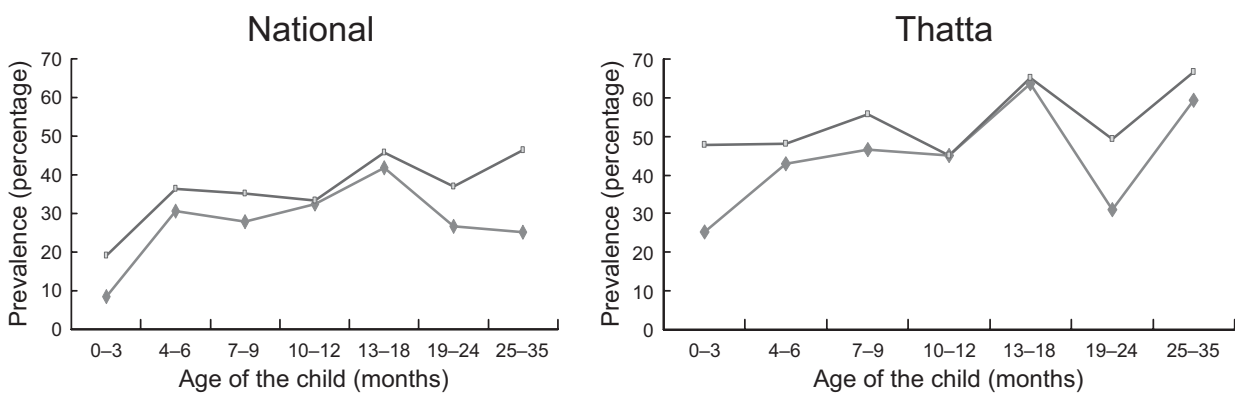

Fig. 2 Percentage prevalence of stunting by age with the WHO ( - ) standard and the National Center for Health Statistics $(\neg-)$ reference for national and Thatta data
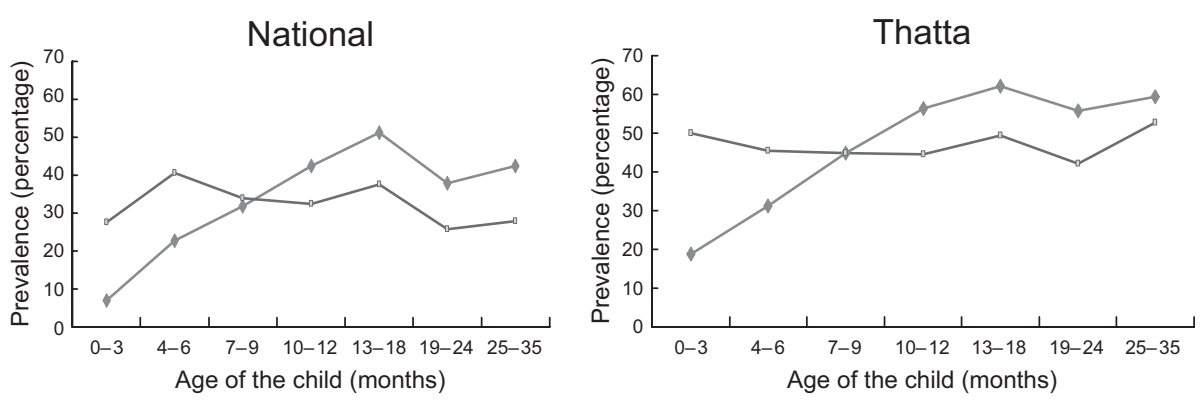

Fig. 3 Percentage prevalence of underweight by age with the WHO $(-\square)$ standard and the National Center for Health Statistics $(-)$ reference for national and Thatta data

indicator, age group and severity of under-nutrition. The high prevalence of under-nutrition in the Thatta compared to the national sample suggests that malnutrition is a very serious problem in this rural subset of the population. The WHO standard resulted in relatively higher overall prevalence of wasting and stunting and a relatively lower overall prevalence of underweight, similar to that observed in Bangladesh National Demographic and Health Survey (1996-97) ${ }^{(21)}$.

Compared to the NCHS reference, the growth pattern based on the WHO standard suggests a higher prevalence of wasting during the first 9 months, of stunting among 0-35-month-olds and of underweight during the first half of infancy (0-6 months). This is consistent with the predictions of a WHO group of experts ${ }^{(21)}$. It is interesting to note that use of the WHO standard showed higher prevalence of under-nutrition for all the three parameters during early life, including infants 0-3 months old. This indicates that under-nutrition in Pakistani children begins at a very early stage of infancy, even before weaning age. This could be related to poor maternal nutrition or health and low birth weight ${ }^{(33)}$, suggesting that children are born malnourished ${ }^{(34)}$. Relative increase in the prevalence of severe under-nutrition with the new standard would influence enrolling of children in therapeutic feeding programmes based on the criterion of severe wasting ${ }^{(35)}$.

\section{Study limitations}

A number of methodological issues require attention. Misclassification of children as underweight or stunted is possible as age assessment was mainly based on recall of birth event and not on birth certificates. Use of a birth cohort would prevent the problem of age assessment and, hence, possible misclassification. In addition, age reporting in whole months could be another source of misclassification of nutritional status ${ }^{(32)}$. As a result, the nutritional status of children whose actual ages were less or more than the nearest month could be under- or overestimated, respectively. For the entire population, although this effect can be balanced if the ages are equally distributed throughout the period (between the middle of the two months), such a distribution cannot be ensured and hence the possibility of misclassification remains. Prevalence of stunting and underweight obtained from computed ages and by ages rounded to the nearest month is, however, closely related ${ }^{(32)}$. In a situation such as ours, where accurate age information is often not available, wasting serves as a useful parameter since it does not require knowledge of the child's age ${ }^{(36)}$.

\section{Conclusion: public bealtb implications}

Use of the WHO standard provides new estimates of nutritional status. These should be taken into account while planning and implementing child health services 
and programmes. Under-nourished infants who are more likely to be missed under the old method than the older children are obvious beneficiaries of the new growth standard. We recommend that nutritional interventions and programmes should be especially targeted to infants (the most vulnerable group). Early onset of under-nutrition in our population points that improvement of children's nutrition is dependent on improving maternal health and nutrition. Hence, maternal health promotion should be made an integral component of child survival programmes.

Since Millennium Development Goal 1 (1990-2015) aims to halve underweight prevalence among underfive children based on the WHO standard, the target for Pakistan would now be reduction from $32 \%$ (based on national data) to $16 \%$. This is lower than reported earlier (20\%) based on the NCHS reference ${ }^{(37)}$. Hence, accelerated efforts are needed to achieve the new target.

We recommend that Pakistan switch to the more robustly constructed and up-to-date WHO standard for assessing nutritional status of pre-school children. Otherwise, a significant proportion of wasted and stunted children who are at risk of excessive morbidity and mortality would be missed ${ }^{(38)}$. A change in the growth standard will also influence the country's ranking internationally by nutritional status and redefinition of the target population for nutritional interventions. The introduction of new standard would require re-analysis of earlier datasets based on the WHO standard for trend monitoring. Allocation of additional resources by policy makers would be needed for the introduction of new growth charts and for training of public and private health workers in their use and interpretation.

\section{Acknowledgements}

Conflicts of interest: The authors declare that there is no conflict of interest.

Funding support: Thatta Health System Research Project was provided by International Development Research Center (IDRC), Canada, and for National Health Survey of Pakistan by the US Government through the PL/480 Program.

Authors' contributions: R.N. participated in the design of survey, conceived and designed the study, performed the literature review and data analysis and drafted the manuscript. M.K.L. participated in the study design and data interpretation and in revising the paper critically for substantial intellectual content. W.C.H. participated in the data interpretation and in revising the paper critically for substantial intellectual content. I.A. participated in the data organisation and interpretation.

We acknowledge Professor Gregory Pappas and Professor Zulifqar Ahmed Bhutta for critically reviewing the manuscript.

\section{References}

1. de Onis M \& Onyango AW (2003) The Centers for Disease Control and Prevention 2000 growth charts and the growth of breastfed infants. Acta Paediatr 92, 413-419.

2. UNICEF (2006) Progress for Children: A Report Card on Nutrition (No. 4). http://www.unicef.org/publications/ index_33685.html

3. Robert SB \& Dallal GE (2001) The new childhood growth charts. Nutr Rev 59, 31-36.

4. de Onis M \& Habicht JP (1996) Anthropometric reference data for international use: recommendations from a World Health Organization Expert Committee. Am J Clin Nutr 64 , 650-658

5. de Onis M, Garza C \& Habicht JP (1997) Time for a New Growth Reference. Pediatrics 100; available at http:// www.pediatrics.org/cgi/content/full/100/5/e8

6. Victora CG, Morris SS, Barros FC, de Onis M \& Yip R (1998) The NCHS reference and the growth of breast-and bottlefed infants. J Nutr 128, 1134-1138.

7. de Onis M \& Yip R (1996) The WHO Growth Chart: historical considerations and current scientific issues. Bibl Nutr Dieta 53, 74-89.

8. WHO Working Group on Infant Growth (1995) An evaluation of infant growth: the use and interpretation of anthropometry in infants. Bull World Health Organ 73, 165-174.

9. Zuguo M, Ray Y, Grummer-Strawn LM \& Trowbridge FL (1998) Development of a research child growth reference and its comparison with the current international growth reference. Arch Pediatr Adolesc Med 152, 471-479.

10. Garza C \& de Onis M (1999) A new international growth reference for young children. Am J Clin Nutr 70, Suppl., 169S-172S.

11. Pan American Health Organization/World Health Organization (2004) Promotion of the New WHO Child Growth Standards. Regional Meeting Report, pp. 1-34. Washington DC: $\mathrm{PAHO} / \mathrm{WHO}$.

12. Bhandari N, Bahl R, Taneja S, de Onis M \& Bhan MK (2002) Growth performance of affluent Indian children is similar to that in developed countries. Bull World Health Organ 80, 189-195.

13. Mohamed AJ, Onyango AW, de Onis M, Prakash N, Mabry TM \& Alasfor DH (2004) Socioeconomic predictors of unconstrained child growth in Muscat, Oman. East Mediterr Health J 10, 295-302.

14. Owusu WB, Lartey A, de Onis M, Onyango AW \& Frongillo EA (2004) Factors associated with unconstrained growth among affluent Ghanaian children. Acta Paediatr 93, $1115-1119$.

15. Garza C \& de Onis M (2007) Introduction. Symposium: A New 21st-Century International Growth Standard for Infants and Young Children. J Nutr 137, 142-143.

16. WHO Multicentre Growth Reference Study Group (2006) WHO Child Growth Standards based on length/height, weight and age. Acta Paediatr Suppl 450, 76-85.

17. WHO Multicentre Growth Reference Study Group (2006) Assessment of differences in linear growth among populations in the WHO Multicentre Growth Reference Study. Acta Pediatr Suppl 450, 56-65.

18. de Onis M, Garza C, Onyango AW \& Borghi E (2007) Comparison of the WHO child growth standards and the CDC 2000 growth charts. Symposium: A New 21st-Century International Growth Standard for Infants and Young Children. J Nutr 137, 144-148.

19. de Onis M, Wijnhoven TMA \& Onyango AW (2004) Worldwide practices in child growth monitoring. J Pediatr 144, 461-465.

20. Onyango AW, de Onis M, Caroli M, Shah U, Sguassero Y, Redondo N \& Carroli B (2007) Field-testing the WHO Child Growth Standards in four countries. Symposium: a New 
21st-Century International Growth Standard for Infants and Young Children. J Nutr 137, 149-152.

21. de Onis M, Onyango AW, Borghi E, Garza C \& Yang H (2006) WHO Multicentre Growth Reference Study Group. Comparison of the World Health Organization (WHO) Child Growth Standards and the National Center for Health Statistics/WHO international growth reference: implications for child health programmes. Public Health Nutr 9, 942-947.

22. Pakistan Medical Research Council (1998) National Health Survey of Pakistan: Health Profile of People of Pakistan, 1990-94, pp. 168-181. Islamabad: Pakistan Medical Research Council, Federal Bureau of Statistics and Department of Health and Human Services.

23. Qureshi AA, Wajid G, Shaikh IA et al. (1992) Ethical considerations for human investigation in the National Health Survey of Pakistan. Pak J Med Res 31, 270-274.

24. Hadden WC, Pappas G \& Khan AQ (2003) Social stratification, development and health in Pakistan: an empirical exploration of relationships in population-based national health examination survey data. Soc Sci Med 57, 1863-1874.

25. Pappas G, Akhtar T, Gergen PT, Hadden WC \& Khan AQ (2001) Health status of the Pakistani population: A health profile and comparison with the United States. Am J Public Health 91, 93-98.

26. Noor Ali R, Hirani A, Hussain HF, Amir Ali N \& Jan A (1994/ 1995) Thatta Health System Research Project, Phase III Year 2 Report, B1, pp. 1-16. Karachi \& Ottawa: Aga Khan University, Department of Health, Sindh \& International Development Research Centre.

27. Noorani NA, Sohani SB, Omair A et al. (1993/1994) Thatta Health System Research Project, Phase III Year 1 Report, B1, pp. 1-5. Karachi \& Ottawa: The Aga Khan University, Department of Health, Sindh \& International Development Research Centre.
28. de Onis M \& Blossner M (1997) WHO Global Database on Child Growth and Malnutrition, pp. 1-65. Geneva: World Health Organization.

29. Altman DG (2000) Practical Statistics for Medical Research. London: Chapman \& Hall.

30. Research Triangle Institute (2004) Software for the Statistical Analysis of Correlated Data, Release 9.0 Version. Research Triangle Park, NC: Research Triangle Institute.

31. UNICEF (not dated) Definitions: Nutrition. http://www. unicef.org/french/infobycountry/stats_popup2.html

32. Gorstein J (1989) Assessment of nutritional status: effects of different methods to determine age on the classification of under nutrition. Bull World Health Organ 67, 143-150.

33. Rikimaru T, Yartey JE, Taniguchi K, Kennedy DO \& Nkrumah FK (1998) Risk factors for the prevalence of malnutrition among urban children in Ghana. J Nutr Sci Vitaminol (Tokyo) 44, 391-407.

34. IFPRI (1992) Second Report on the World Nutrition Situation - Volume I: Global and Regional Results. Chapter 1: Stunting and Young Child Development. http:// www.unsystem.org/scn/archives/rwns03/ch06.htm\#b5-Born\% 20malnourished

35. WHO Multicentre Growth Reference Study Group (2006) WHO Child Growth Standards: Length/Height-for-age, Weight-for-age, Weight-for-length, Weight-for-height and Body Mass Index-for age: Methods and Development. Geneva: World Health Organization.

36. Cole TJ (1993) The use and construction of anthropometric growth reference standards. Nutr Res Rev 6, 19-50.

37. Bhutta ZA (2004) Pakistan and the millennium development goals for health: a case of too little, too late? J Coll Phys Surg Pak 14, 515-517.

38. Pelletier DL \& Frongillo EA (2003) Changes in child survival are strongly associated with changes in malnutrition in developing countries. J Nutr 133, 107-119. 